\title{
Prognostic Significance of Lymph Node Ratio after Cervical Lymph Node Dissection in Head and Neck Squamous Cell Carcinoma
}

\author{
Wafaa El-beshbeshi ${ }^{1}$, Amir M. Zaid ${ }^{2}$, Osama Eldamshety ${ }^{2}$, Islam H. Metwally ${ }^{2}$, Entsar \\ Eladl ${ }^{3}$, Engy M. Aboelnaga ${ }^{1}$
}
${ }^{1}$ Department of Clinical Oncology and Nuclear Medicine, Faculty of Medicine, Mansoura University, Mansoura, Egypt; ${ }^{2}$ Department of Surgical Oncology, Oncology Center, Faculty of Medicine, Mansoura University, Mansoura, Egypt; ${ }^{3}$ Department of Pathology, Faculty of Medicine, Mansoura University, Mansoura, Egypt

Background: Lymph node ratio (LNR) is the number of positive lymph nodes (LNs) divided by the total number of excised nodes. It has been shown to be of prognostic significance in a number of cancers.

Aim: To investigate the relation between LNR and survival of patients with head and neck squamous cell carcinoma (HNSCC).

Methods: A retrospective study of 115 patients with HNSCC treated with curative surgery including neck dissection \pm adjuvant treatment from January 2013 to December 2017.

Results: The median LNR among node-positive patients was 0.14 which was used as a cutoff point to divide patients into two risk groups. Male gender, N2 stage, high grade and extranodal extension were significantly associated with high ( $\geq 0.14$ ) LNR. In multivariate analysis, high LNR, higher TNM nodal stage and larger absolute number of positive LNs associated significantly with worse overall and disease-free survival. In a subgroup analysis of node-positive cases ( $n=54)$, LNR associated significantly with disease-free survival but not overall survival. On the other hand, the absolute number of positive LNs and N stage had a significant effect on both overall and disease-free survival.

Conclusion: The LNR is of prognostic significance for survival and disease failure in HNSCC. This is also true for the absolute number of positive LNs. Standardization of LN status assessment and determination of an agreed upon cutoff value for LNR are needed before considering its incorporation in the staging system and treatment strategy.

Keywords: Head and neck, Lymph node ratio, Lymph node stage, Prognosis, Squamous cell carcinoma Corresponding author: Engy M. Aboelnaga, MD; Department of Clinical Oncology and Nuclear Medicine, Faculty of Medicine, Mansoura University, Mansoura, Egypt; Email: engyms2007@gmail.com

Submitted: 14-March-2020, Revised: 27-May-2020, Accepted: 31-May-2020, Published online: 29-June-2020

(cc) BY

\section{INTRODUCTION}

Head and neck squamous cell carcinoma (HNSCC) is amongst the common malignant tumor worldwide. The main line of treatment is surgical interference. Chemotherapy, radiotherapy or their combinations following surgery are reserved for the treatment of advanced stage ${ }^{1}$. However, a subgroup of patients experience relapse following surgery and adjuvant therapy. Therefore, it is important to promote treatment outcome by detecting credible prognostic factors that define HNSCC patients at high risk of disease failure ${ }^{2}$.

Cancer staging is a crucial procedure that assists physicians, researchers and patients to know about the disease status, prognosis, and different treatment lines. The most common staging system used for head and neck cancer is that of the American Joint Committee on Cancer (AJCC). This system is based on TNM staging and combines data on the number, size as well as the laterality of positive lymph nodes (LNs) ${ }^{3}$. The $8^{\text {th }}$ edition of the AJCC manual applied some modifications for oral cavity, pharynx and larynx cancers. Recently, tumor depth as well as extranodal extension (ENE) are detrimental factors to be considered in the staging system in addition to the aforementioned factors ${ }^{4}$.

Lymph node status is an essential factor to be considered in the prognosis of HNSCC. Accordingly, initial examination of LNs is a fundamental part of the staging system ${ }^{5}$. Researchers have suggested that the lymph node ratio (LNR) may be superior to the AJCC staging of LNs in assessing disease prognosis ${ }^{6,7}$. Lymph node ratio is defined as the ratio of the number of positive LNs to the total number of excised LNs, and it has been previously used as prognostic factor in patients with bladder, esophageal, colorectal, breast and cervical cancers ${ }^{8-12}$. Some studies highlighted that the LNR may anticipate the clinical outcomes in patients with HNSCC 13,14 . It is worth noting that there are three factors playing a crucial role in the accuracy of LNR; the number of excised LNs, positivity of LNs and the accuracy of pathological examination ${ }^{15}$.

We aimed to assess the impact of LNR as an independent prognostic factor on the overall survival (OS) and disease-free survival (DFS) in HNSCC, as well 
as the prognostic value of the absolute number of positive LNs.

\section{METHODS}

We retrospectively reviewed the data of patients diagnosed with HNSCC from January 2013 to December 2017 at Clinical Oncology and Nuclear Medicine Department, and Oncology Center, Mansoura University, Mansoura, Egypt.

\section{Patients and data collection}

The inclusion criteria were confirmed pathological diagnosis of HNSCC, complete pre-treatment staging assessment, no distant metastasis at time of diagnosis and radical tumor excision with LN neck dissection. Exclusion criteria included treatment with neoadjuvant chemo-radiotherapy, deficient data and incomplete follow up.

The following data were reviewed: age, sex, anatomical site of the primary lesion, type and level of LN neck dissection, tumor size staging (T1-T2, T3-T4), and nodal staging (N0, N1, N2a, N2b, N2c), total number of dissected LNs, absolute number of positive LNs, LNR, tumor differentiation, status of surgical margin, lymphovascular invasion (LVI), perineural invasion (PNI), ENE , type of adjuvant treatment and follow up data including treatment failure and survival data. The final staging was based on the AJCC TNM classification system $7^{\text {th }}$ edition.

\section{Lymph node ratio}

The LNR was calculated as the total number of positive LNs divided by the total nodal yield in lymph node-positive patients. To test its prognostic significance; we used the median LNR value of 0.14 that we found to divide patients into low risk $(<0.14)$ and high risk $(\geq$ $0.14)$ LNR groups. In addition, we tested a previously reported LNR cutoff values classifying patients into three risk groups: low $(0<0.06)$, intermediate $(0.06$ to $\leq 0.17)$ and high $(>0.17)^{2}$. Patients with negative LNs were assigned to the LNR low risk group.

Furthermore, the prognostic significance of the absolute number of positive LNs was tested. Patients were grouped according to the number of positive LNs into three groups (0-1, 2-3 and $\geq 4$ positive LNs) and survival was compared between them.

\section{Adjuvant treatment}

Post-operative radiotherapy was delivered in the presence of risk factors using 3-dimensional conformal radiotherapy with 6- MV energy photon beam in a dose of 60-66 Gy / 1.8-2.0 Gy per fraction. While adjuvant concurrent chemotherapy was administrated in fit patients with high risk factors as positive margin and /or ENE. Chemotherapy was used in form of cisplatin $100 \mathrm{mg} / \mathrm{m}^{2}$ every 3 weeks or $40 \mathrm{mg} / \mathrm{m}^{2}$ weekly.

\section{Statistical analysis}

Data was described as number (percentage) or median (range). Chi-square or Fisher's exact test was used for comparison of categorical data where appropriate.
The endpoints were OS and DFS. The OS was estimated from the date of diagnosis to the date of death from any reason. The DFS was calculated from the date of surgery to the date of disease recurrence (local or distant) or death from any cause. Patients with no events at the time of analysis were censored at the date of last follow up. Survival curves were estimated using the Kaplan-Meier method. Univariate and multivariate Cox regression analysis was used to test the association between variables and survival. A p-value of less than 0.05 was considered statistically significant.

The statistical analyses were conducted using the Statistical Package for the Social Sciences (SPSS) version 20.0 and MeCalc version 19.3.1 software for Windows.

\section{Ethical considerations}

The study protocol was approved by the Institutional Review Board of the Faculty of Medicine, Mansoura University (approval \# 19.05.509)

\section{RESULTS}

One hundred and fifteen patients with HNSCC were eligible for inclusion. Patients and disease characteristics and treatment summary are presented in Table 1 . Tongue was the commonest 1ry site and one third of patients had an advanced $\mathrm{T}$ stage (T3-4). Unilateral selective neck dissection was the most performed neck dissection and the number of dissected LNs was $<10$ in $40(34.7 \%)$. Positive nodes were detected in $54(47 \%)$ patients and their median number was 2 (range: 1-11). The approximate median LNR in node-positive patients was 0.14 which was used as a cutoff value in this study to divide patients into low $(<0.14)$ and high $(\geq 0.14)$ groups.

The relation between LNR and the other studied variables is described in Table 2. Higher LNR was significantly associated with male gender, higher $\mathrm{N}$ stage, higher grade and the presence of ENE.

After a median follow up period of 22 months (range: $7-84$ ), the 3-year and 5-year OS rates were $75.5 \%$ and $49.2 \%$ with a mean $59 \pm 5.4$ months $(95 \%$ Confidence Interval [CI]: 48.7-70.0). The 3-year and 5-year DFS rates were $57.7 \%$ and $52.9 \%$, with a mean $40.5 \pm 2.4$ months (95\% CI: 35.6-45.4).

Disease failure occurred in $44(38.3 \%)$ patients which was locoregional in $32(27.8 \%)$, distant in $4(3.5 \%)$ and mixed in $8(7 \%)$. Among the 88 patients in the low LNR group, $20(22.7 \%)$ patients had local recurrence, $2(2.3 \%)$ had distant metastases and $3(3.4 \%)$ had both. While in the 27 patients of the high LNR group, $12(44.4 \%)$ had local recurrence, $2(7.4 \%)$ had distant metastases and 5 $(18.5 \%)$ had both. The recurrence rate was significantly higher in the high LNR group $(\mathrm{p}<0.001)$.

In univariate survival analysis, the following factors were significantly associated with decreased OS: high LNR (Figure 1), high N stage, larger number of positive LNs grouping (Figure 2), higher tumor grade, and not receiving adjuvant treatment. While factors associated with lower DFS were high LNR (Figure 3), higher N stage, larger number of positive LNs (Figure 4) higher tumor grade, ENE, LVI, PNI, and not receiving adjuvant treatment. Table 3 summarized this analysis. 
Table 1: Patients and disease characteristics and treatment

\begin{tabular}{|c|c|c|}
\hline Variable & & No. $(\%) *$ \\
\hline Age (years) & Median (range) & $58(25-76)$ \\
\hline \multirow[t]{2}{*}{ Sex } & Male & $87(75.7)$ \\
\hline & Female & $28(24.3)$ \\
\hline \multirow[t]{4}{*}{ Site } & Tongue & $53(46.1)$ \\
\hline & Larynx & $42(36.5)$ \\
\hline & Lip & $13(11.3)$ \\
\hline & Other oral cavity & $7(6.1)$ \\
\hline \multirow[t]{4}{*}{ T stage } & $\mathrm{T} 1$ & $32(27.8)$ \\
\hline & $\mathrm{T} 2$ & $49(42.6)$ \\
\hline & T3 & $24(20.9)$ \\
\hline & $\mathrm{T} 4$ & $10(8.7)$ \\
\hline \multirow[t]{5}{*}{ N stage } & N0 & $61(53)$ \\
\hline & N1 & $17(14.8)$ \\
\hline & $\mathrm{N} 2 \mathrm{a}$ & $14(12.2)$ \\
\hline & $\mathrm{N} 2 \mathrm{~b}$ & $18(15.7)$ \\
\hline & $\mathrm{N} 2 \mathrm{c}$ & $5(4.3)$ \\
\hline LN retrieval & Median (range) & $12(3-53)$ \\
\hline \multirow{3}{*}{$\begin{array}{l}\text { Absolute number of } \\
\text { positive LNs groups }\end{array}$} & $0-1$ & $79(68.7)$ \\
\hline & $2-3$ & $24(20.9)$ \\
\hline & $\geq 4$ & $12(10.4)$ \\
\hline $\begin{array}{l}\text { LNR in node-positive } \\
\text { patients }\end{array}$ & Median (range) & $\begin{array}{l}0.138 \\
(0.023-1)\end{array}$ \\
\hline \multirow[t]{4}{*}{ Grade } & I & $38(33)$ \\
\hline & II & $62(53.9)$ \\
\hline & III & $13(11.3)$ \\
\hline & Missing & $2(1.7)$ \\
\hline \multirow[t]{3}{*}{ Extranodal extension } & No & $85(73.9)$ \\
\hline & Yes & $15(13)$ \\
\hline & Missing & $15(13)$ \\
\hline \multirow[t]{3}{*}{ Perineural invasion } & No & $76(66.1)$ \\
\hline & Yes & $25(21.7)$ \\
\hline & Missing & $14(12.2)$ \\
\hline \multirow{3}{*}{$\begin{array}{l}\text { Lymphovascular } \\
\text { invasion }\end{array}$} & No & $85(73.9)$ \\
\hline & Yes & $17(14.8)$ \\
\hline & Missing & $13(11.3)$ \\
\hline \multirow[t]{5}{*}{ Neck dissection } & Supra-omohyoid & $21(18.2)$ \\
\hline & Selective & $38(33.1)$ \\
\hline & Radical & $15(13.1)$ \\
\hline & Bilateral & $32(27.8)$ \\
\hline & Missing & $9(7.8)$ \\
\hline \multirow[t]{3}{*}{ Resection margin } & Free & $96(83.5)$ \\
\hline & Infiltrated & $15(13)$ \\
\hline & Missing & $4(3.5)$ \\
\hline \multirow[t]{3}{*}{ Adjuvant treatment } & None & $48(41.7)$ \\
\hline & $\begin{array}{l}\text { Chemo- } \\
\text { radiotherapy }\end{array}$ & $43(37.4)$ \\
\hline & Radiotherapy & $24(20.9)$ \\
\hline \multirow[t]{4}{*}{ Disease failure pattern } & Loco-regional & $32(27.8)$ \\
\hline & Distant & $4(3.5)$ \\
\hline & Both & $8(7)$ \\
\hline & None & $71(61.7)$ \\
\hline
\end{tabular}

*Unless otherwise specified; LN: Lymph node; LNR: Lymph node ratio
Table 2: The relation between $\mathrm{LNR}$ and prognostic factors

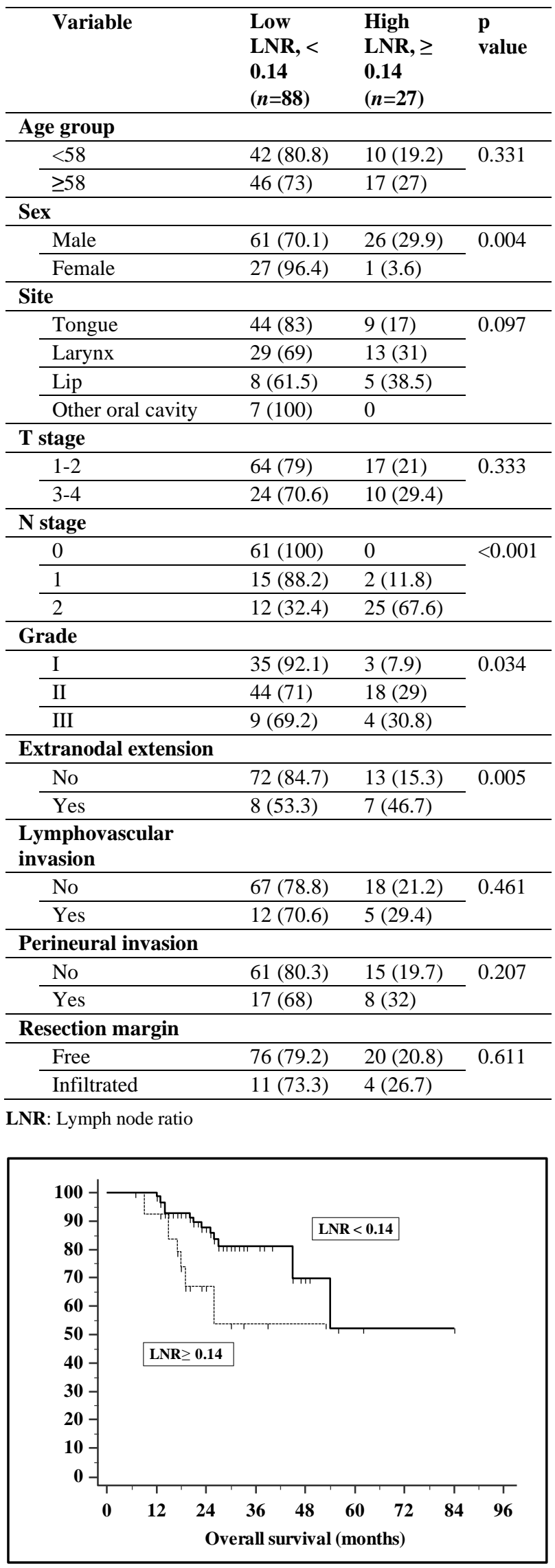

Figure 1: Kaplan-Meier curves of overall survival according to lymph node ratio (LNR) 


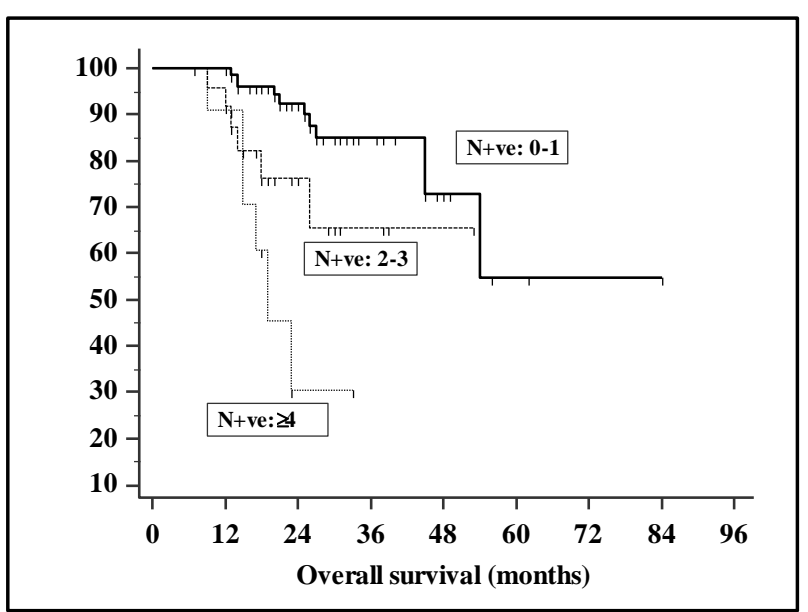

Figure 2: Kaplan-Meier curves of overall survival according to the absolute number of +ve lymph nodes

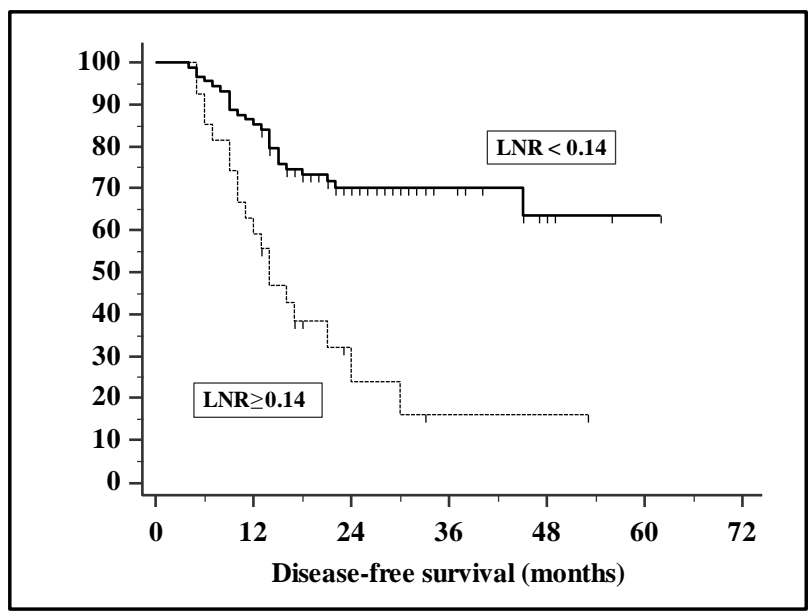

Figure 3: Kaplan-Meier curves of disease-free survival according to lymph node ratio (LNR)

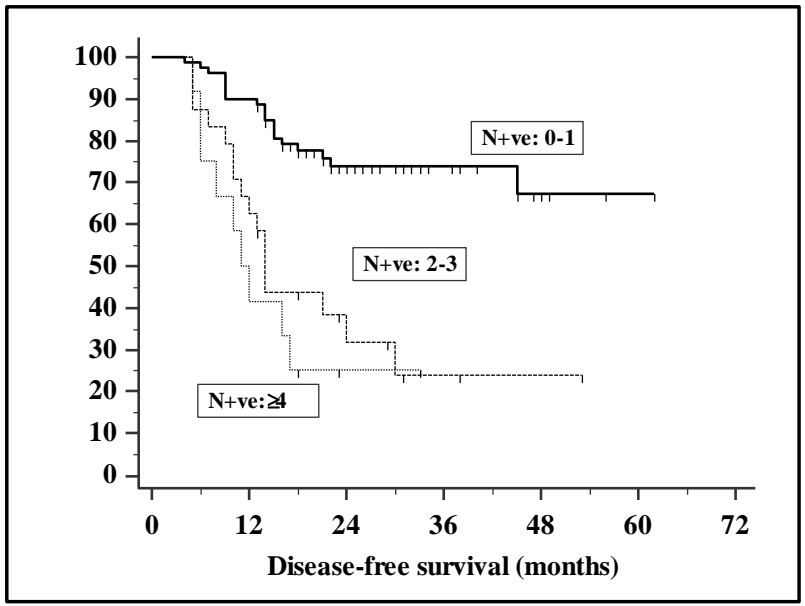

Figure 4: Kaplan-Meier curves of overall survival according to the absolute number of +ve lymph nodes

By using the predefined LNR cutoff values to divide patients into 3 groups (low $[<0.06]$, intermediate [0.06 to $\leq 0.17]$ and high [ $>0.17]$ risk groups), we found significant relation to OS $(\mathrm{p}=0.011)$ and DFS $(\mathrm{p}<0.001)$. There was a significant relation between low risk and high risk ( $\mathrm{p}=0.004)$, but not between intermediate risk and low or high risk ( $\mathrm{p}=0.43$ and $\mathrm{p}=0.17$, respectively). For DFS, there were significant relation between low risk and both intermediate and high risk $(\mathrm{p}=0.028$ and $\mathrm{p}<0.001$, respectively), but not between intermediate and high risk $(\mathrm{p}=0.13)$.

To avoid multicollinearity, LNR, N stage and number of positive LNs were not included in single multivariate Cox regression analysis. For each, Cox regression analysis was performed to test its independent significance adjusted for other variables (Tables 4, 5 and 6).

In multivariate analysis, LNR maintained its significance for both OS and DFS (Table 4). The same was for 2-3 and $\geq 4$ positive LNs when compared to 0-1 positive LNs (Table 5). Only N2 was of independent significance for OS and DFS when compared to N0, but not N1 (Table 6).

In subgroup analysis of cases with positive LNs $(n=54)$, LNR was not significant in univariate analysis for OS but was significant for DFS. On the other hand, the number of positive LNs and $\mathrm{N}$ stage correlated significantly with OS and DFS (Table 7).

\section{DISCUSSION}

Cervical LN involvement is greatly accepted as an important prognostic factor for HNSCC and is associated with poor prognosis. The number, size, and laterality of positive nodes are integrated in the $\mathrm{N}$ classification of the AJCC TNM staging ${ }^{3}$. Another prognostic factor related to nodal metastasis is the ENE which has been incorporated recently in the $8^{\text {th }}$ edition of the Union for International Cancer Control classification and staging system. In this staging system cases with ENE are classified in a higher $\mathrm{N}$ stage ${ }^{4}$.

Another poor prognostic factor was recently identified in many cancers which is the LNR or LN density ${ }^{8-12}$. The LNR is affected by the extent of LN dissection and the levels of dissection, which gives a good idea about the burden of the tumor. Moreover, it is a good index for surgical and pathology standards ${ }^{13}$. Marres et al. reported that LNR is dependent on both the pathological processing technique and the extent of the surgical dissection ${ }^{16}$. Based on this, for adequate neck dissection and accurate assessment of the number of positive nodes, the number of resected nodes is stated by AJCC TNM classification system as 10 or more in selective neck dissection, and 15 or more in comprehensive neck dissection. The number of $\mathrm{LN}$ yield is required for accurate staging and detection of micrometastasis ${ }^{17-19}$.

The LNR was investigated in many studies and found to be of significant prognostic value and significant relation to survival and recurrence rate. The importance of LNR was compared to the TNM staging system and showed superiority in previous results ${ }^{2,17}$. However, the incorporation of LNR in the treatment strategy is not established yet. A significant relation between survival and the ratio of neck $\mathrm{LN}$ metastasis was reported in a previous study ${ }^{20}$. On the other hand, another study concluded no significant relation with the total number of excised LNs either positive or negative or the number of detected positive $\mathrm{LNs}^{21}$. 
Table 3: Univariate analysis of overall and disease-free survival of all patients

\begin{tabular}{|c|c|c|c|c|c|}
\hline \multirow[t]{2}{*}{ Variable } & & \multicolumn{2}{|c|}{ Overall survival } & \multicolumn{2}{|c|}{ Disease-free survival } \\
\hline & & HR $(95 \% \mathrm{CI})$ & p value & HR $(95 \%$ CI $)$ & p value \\
\hline \multirow[t]{2}{*}{ Age group } & $<58$ & Ref. & & Ref. & \\
\hline & $\geq 58$ & $1.13(0.49-2.63)$ & 0.77 & $1.24(0.68-2.24)$ & 0.487 \\
\hline \multirow[t]{2}{*}{ Sex } & Male & Ref. & & Ref. & \\
\hline & Female & $1.05(0.42-2.61)$ & 0.919 & $0.72(0.34-1.49)$ & 0.37 \\
\hline \multirow[t]{4}{*}{ Site } & Larynx & Ref. & & Ref. & \\
\hline & Lip & $0.7(0.15-3.23)$ & 0.643 & $0.81(0.3-2.17)$ & 0.671 \\
\hline & Other oral & $2.55(0.68-9.53)$ & 0.165 & $1.26(0.37-4.26)$ & 0.713 \\
\hline & Tongue & $0.68(0.26-1.78)$ & 0.435 & $0.74(0.39-1.41)$ & 0.355 \\
\hline \multirow[t]{2}{*}{ T stage } & $\mathrm{T} 1-2$ & Ref. & & Ref. & \\
\hline & T3-4 & $1.03(0.42-2.51)$ & 0.954 & $1.13(0.61-2.11)$ & 0.698 \\
\hline \multirow[t]{3}{*}{ N stage } & No & Ref. & & Ref. & \\
\hline & N1 & $0.34(0.04-2.68)$ & 0.307 & $0.39(0.09-1.71)$ & 0.213 \\
\hline & $\mathrm{N} 2$ & $3.63(1.5-8.78)$ & 0.004 & $3.81(2.05-7.07)$ & $<0.001$ \\
\hline \multirow{3}{*}{$\begin{array}{l}\text { Absolute number of positive } \\
\text { lymph nodes groups }\end{array}$} & $0-1$ & Ref. & & Ref. & \\
\hline & $2-3$ & $3.04(1.09-8.49)$ & 0.034 & $3.75(1.93-7.27)$ & $<0.001$ \\
\hline & $\geq 4$ & $8.48(2.92-24.65)$ & 0.0001 & $5.11(2.31-11.35)$ & $<0.001$ \\
\hline \multirow[t]{3}{*}{ Grade } & I & Ref. & & Ref. & \\
\hline & II & $4(1.13-14.18)$ & 0.032 & $2.53(1.15-5.57)$ & 0.021 \\
\hline & III & $5.3(1.15-24.45)$ & 0.033 & $3.07(1.11-8.49)$ & 0.031 \\
\hline \multirow[t]{2}{*}{ Extranodal extension } & No & Ref. & & Ref. & \\
\hline & Yes & $1.97(0.66-5.92)$ & 0.228 & $3.6(1.81-7.15)$ & $<0.001$ \\
\hline \multirow[t]{2}{*}{ Lymphovascular invasion } & No & Ref. & & Ref. & \\
\hline & Yes & $2.11(0.8-5.53)$ & 0.129 & $2.23(1.11-4.47)$ & 0.025 \\
\hline \multirow[t]{2}{*}{ Perineural invasion } & No & Ref. & & Ref. & \\
\hline & Yes & $1.47(0.57-3.8)$ & 0.429 & $2.73(1.45-5.13)$ & 0.002 \\
\hline \multirow[t]{2}{*}{ Resection margin } & Free & Ref. & & Ref. & \\
\hline & Infiltrated & $1.52(0.49-4.69)$ & 0.467 & $1.68(0.78-3.65)$ & 0.187 \\
\hline \multirow[t]{2}{*}{ Lymph node ratio } & $<0.14$ & Ref. & & Ref. & \\
\hline & $\geq 0.14$ & $2.96(1.22-7.2)$ & 0.017 & $3.44(1.89-6.26)$ & $<0.001$ \\
\hline \multirow[t]{3}{*}{ Adjuvant treatment } & None & Ref. & & Ref. & \\
\hline & Radiotherapy & $0.11(0.02-0.84)$ & 0.033 & $0.32(0.12-0.84)$ & 0.02 \\
\hline & Chemo-radiotherapy & $0.36(0.13-0.99)$ & 0.048 & $0.59(0.31-1.13)$ & 0.112 \\
\hline
\end{tabular}

CI: Confidence interval

Table 4: Multivariate analysis for the relation between lymph node ratio and survival

\begin{tabular}{|c|c|c|c|c|c|}
\hline \multirow[t]{2}{*}{ Variables } & & \multicolumn{2}{|c|}{ Overall survival } & \multicolumn{2}{|c|}{ Disease-free survival } \\
\hline & & HR $(95 \% \mathrm{CI})$ & p value & HR $(95 \% \mathrm{CI})$ & p value \\
\hline \multirow[t]{2}{*}{ Lymph node ratio } & $<0.14$ & Ref. & & Ref. & \\
\hline & $\geq 0.14$ & $6.87(1.82-25.94)$ & 0.005 & $2.94(1.16-7.47)$ & 0.023 \\
\hline \multirow[t]{3}{*}{ Grade } & I & Ref. & & Ref. & \\
\hline & II & $6.43(1.55-26.57)$ & 0.01 & $1.81(0.73-4.45)$ & 0.198 \\
\hline & III & $10.82(1.99-58.85)$ & 0.006 & $2.67(0.66-10.7)$ & 0.167 \\
\hline \multirow[t]{2}{*}{ Extranodal extension } & No & NA & & Ref. & \\
\hline & Yes & NA & & $3.8(1.63-8.86)$ & 0.002 \\
\hline \multirow[t]{2}{*}{ Lymphovascular invasion } & No & NA & & Ref. & \\
\hline & Yes & NA & & $3(1.26-7.15)$ & 0.013 \\
\hline \multirow[t]{2}{*}{ Perineural invasion } & No & NA & & Ref. & \\
\hline & Yes & NA & & $2.34(1.1-4.99)$ & 0.028 \\
\hline \multirow[t]{3}{*}{ Adjuvant treatment } & None & Ref. & & Ref. & \\
\hline & Radiotherapy & $0.06(0.01-0.51)$ & 0.01 & $0.3(0.1-0.87)$ & 0.027 \\
\hline & Chemo-radiotherapy & $0.11(0.03-0.42)$ & 0.002 & $0.23(0.09-0.6)$ & 0.003 \\
\hline
\end{tabular}

CI: Confidence interval, NA: Not applicable 
Table 5: Multivariate analysis for the relation between absolute number of positive lymph nodes and survival

\begin{tabular}{|c|c|c|c|c|c|}
\hline \multirow[t]{2}{*}{ Variables } & & \multicolumn{2}{|c|}{ Overall survival } & \multicolumn{2}{|c|}{ Disease-free survival } \\
\hline & & HR $(95 \%$ CI $)$ & p value & HR (95\% CI) & p value \\
\hline \multirow{3}{*}{$\begin{array}{l}\text { Absolute number of positive } \\
\text { lymph nodes groups }\end{array}$} & $0-1$ & Ref. & & Ref. & \\
\hline & $2-3$ & $22.79(4.56-113.8)$ & $<0.001$ & $4.78(1.74-13.17)$ & 0.002 \\
\hline & $\geq 4$ & 78.44 (12.4-496.09) & $<0.001$ & $27.99(7.06-111.02)$ & $<0.001$ \\
\hline \multirow[t]{3}{*}{ Grade } & I & Ref. & & Ref. & \\
\hline & II & $8.46(1.79-39.9)$ & 0.007 & $1.98(0.8-4.93)$ & 0.142 \\
\hline & III & $19(3.07-117.44)$ & 0.002 & $2.29(0.51-10.29)$ & 0.278 \\
\hline \multirow[t]{2}{*}{ Extranodal extension } & No & NA & & Ref. & \\
\hline & Yes & NA & & $6.02(2.4-15.07)$ & $<0.001$ \\
\hline \multirow[t]{2}{*}{ Lymphovascular invasion } & No & NA & & Ref. & \\
\hline & Yes & NA & & $4.04(1.58-10.32)$ & 0.004 \\
\hline \multirow[t]{2}{*}{ Perineural invasion } & No & NA & & Ref. & \\
\hline & Yes & NA & & $2.38(1.11-5.13)$ & 0.026 \\
\hline \multirow[t]{3}{*}{ Adjuvant treatment } & None & Ref. & & Ref. & \\
\hline & Radiotherapy & $0.01(0.001-0.13)$ & $<0.001$ & $0.22(0.07-0.74)$ & 0.015 \\
\hline & Chemo-radiotherapy & $0.04(0.01-0.19)$ & $<0.001$ & $0.1(0.03-0.29)$ & $<0.001$ \\
\hline
\end{tabular}

CI: Confidence interval, NA: Not applicable

Table 6: Multivariate analysis for the relation between $\mathrm{N}$ stage and survival

\begin{tabular}{|c|c|c|c|c|c|}
\hline \multirow[t]{2}{*}{ Variables } & & \multicolumn{2}{|c|}{ Overall survival } & \multicolumn{2}{|c|}{ Disease-free survival } \\
\hline & & HR (95\% CI) & p value & HR $(95 \%$ CI) & p value \\
\hline \multirow{3}{*}{ N stage } & 0 & Ref. & & Ref. & \\
\hline & 1 & $2.22(0.23-21.27)$ & 0.49 & $1.01(0.18-5.63)$ & 0.995 \\
\hline & 2 & $36.31(7.2-183.04)$ & $<0.001$ & $8.41(2.98-23.71)$ & $<0.001$ \\
\hline \multirow[t]{3}{*}{ Grade } & $\mathrm{I}$ & Ref. & & Ref. & \\
\hline & II & $11.36(2.28-56.65)$ & 0.003 & $2.09(0.8-5.5)$ & 0.135 \\
\hline & III & $19.43(2.86-131.91)$ & 0.002 & $1.36(0.3-6.1)$ & 0.691 \\
\hline \multirow[t]{2}{*}{ Extranodal extension } & No & NA & & Ref. & \\
\hline & Yes & NA & & $3.58(1.47-8.71)$ & 0.005 \\
\hline \multirow{2}{*}{ Lymphovascular invasion } & No & NA & & Ref. & \\
\hline & Yes & NA & & $2.8(1.17-6.7)$ & 0.021 \\
\hline \multirow[t]{2}{*}{ Perineural invasion } & No & NA & & Ref. & \\
\hline & Yes & NA & & $2.06(0.97-4.36)$ & 0.06 \\
\hline \multirow{3}{*}{ Adjuvant treatment } & None & Ref. & & Ref. & \\
\hline & Radiotherapy & $0.01(0.001-0.13)$ & $<0.001$ & $0.18(0.05-0.62)$ & 0.007 \\
\hline & Chemo-radiotherapy & $0.03(0.01-0.15)$ & $<0.001$ & $0.1(0.03-0.31)$ & $<0.001$ \\
\hline
\end{tabular}

CI: Confidence interval, NA: Not applicable

A meta-analysis including 28 studies was conducted by Talmi et al who concluded that a cutoff value of LNR between 0.02 and 0.2 (average $=0.09$ ) is associated with overall and disease specific survival ${ }^{22}$. There are several methods for the calculation of the LNR cutoff value, the commonest is using the ROC curve ${ }^{13,19}$ or the median of positive $\mathrm{LNs}^{2}{ }^{23}$. We used a cutoff value of 0.14 based on median LNR in positive LNs cases. In that meta-analysis, some studies included only one head and neck site, while others included multiple sites. In our study, the tongue was the most common site followed by larynx.

In the study of Samani et al; based on LNR $\leq 0.06$ and LNR $>0.06$, a significant difference in OS $(p \leq 0.001)$ was noticed and also a significant difference in LNR between different stages of HNSCC $(p<0.05){ }^{24}$. In our study, we found a significant relation between high LNR $(\geq 0.14)$ and higher $N$ stage, higher grade and positive ENE. This may indicate the association of LNR with poor prognostic factors. This finding agrees to some extent with results of Hosni et al who reported a significant association of high LNR $(>0.06)$ with more advanced stage, presence of LVI and PNI ${ }^{15}$. The association between LNR and more advanced stage, higher N stage, higher grade and ENE was also documented by other authors ${ }^{19}$.

The problem of LNR is the variation of cutoff values among studies. Some used an LNR cutoff value of $0.06^{7}$, $15,21,24$, while others used different values of $0.088^{13}$, $0.075^{17,19}$ and $0.1^{2,25}$. Some previous studies were conducted on oral cavity tumors 13, 15, 21 or hypopharyngeal carcinoma ${ }^{14}$. Chen et al included various sites of HNSCC and used an LNR cutoff value of $\geq 0.1$. They found that the 3-year OS and 3-year local failure free survival are lower in patients with higher LNR 2. Other studies used two cutoff values of LNR to categorize patients into low, moderate and high risk groups and analyzed survival outcomes in oral cancer patients ${ }^{17}$. Ratio of $>17 \%$ in Hosni et al maximized the outcome difference on distant or regional failure and OS in oral cavity cancer patients with $\mathrm{N} 2$ stage in comparison to ratio of $>6 \%{ }^{15}$. This is coping with our report that 
Table 7: Univariate analysis of overall and disease-free survival of node-positive patients $(\mathbf{n}=54)$

\begin{tabular}{|c|c|c|c|c|c|}
\hline \multirow[t]{2}{*}{ Variables } & & \multicolumn{2}{|c|}{ Overall survival } & \multicolumn{2}{|c|}{ Disease-free survival } \\
\hline & & HR $(95 \% \mathrm{CI})$ & P-value & HR $(95 \% \mathrm{CI})$ & P-value \\
\hline \multirow{2}{*}{ Age group } & $<58$ & Ref. & & Ref. & \\
\hline & $\geq 58$ & $1.5(0.46-4.89)$ & 0.5 & $1.15(0.54-2.46)$ & 0.714 \\
\hline \multirow[t]{2}{*}{ Sex } & Male & Ref. & & Ref. & \\
\hline & Female & $2.89(0.94-8.88)$ & 0.064 & $1.27(0.51-3.13)$ & 0.605 \\
\hline \multirow[t]{4}{*}{ Site } & Larynx & Ref. & & Ref. & \\
\hline & Lip & $0.45(0.05-3.82)$ & 0.461 & $0.72(0.23-2.24)$ & 0.567 \\
\hline & Other oral & $2.79(0.66-11.8)$ & 0.162 & $1.5(0.42-5.35)$ & 0.532 \\
\hline & Tongue & $0.96(0.26-3.6)$ & 0.953 & $0.79(0.33-1.87)$ & 0.587 \\
\hline \multirow[t]{2}{*}{ T stage } & $\mathrm{T} 1-2$ & Ref. & & Ref. & \\
\hline & $\mathrm{T} 3-4$ & $0.72(0.2-2.63)$ & 0.62 & $1.07(0.48-2.36)$ & 0.874 \\
\hline \multirow[t]{4}{*}{ N stage } & N1 & Ref. & & Ref. & \\
\hline & $\mathrm{N} 2 \mathrm{a}$ & $8.57(0.998-73.66)$ & 0.05 & $8.19(1.76-38.16)$ & 0.007 \\
\hline & $\mathrm{N} 2 \mathrm{~b}$ & $5.91(0.69-50.81)$ & 0.106 & $8.63(1.94-38.36)$ & 0.005 \\
\hline & $\mathrm{N} 2 \mathrm{c}$ & $14.37(1.26-163.48)$ & 0.032 & $14(2.52-77.69)$ & 0.003 \\
\hline \multirow{3}{*}{$\begin{array}{l}\text { Absolute number of positive } \\
\text { lymph nodes groups }\end{array}$} & 1 & Ref. & & Ref. & \\
\hline & $2-3$ & $5.86(0.7-48.77)$ & 0.102 & $5.49(1.59-18.91)$ & 0.007 \\
\hline & $\geq 4$ & $13.8(1.64-116.14)$ & 0.016 & $7.56(2.03-28.18)$ & 0.003 \\
\hline \multirow[t]{3}{*}{ Grade } & $\mathrm{I}$ & Ref. & & Ref. & \\
\hline & II & $2.74(0.58-13.01)$ & 0.204 & $2.96(0.997-8.76)$ & 0.051 \\
\hline & III & $1.02(0.09-11.25)$ & 0.988 & $2.09(0.52-8.39)$ & 0.298 \\
\hline \multirow[t]{2}{*}{ Extranodal extension } & No & Ref. & & Ref. & \\
\hline & Yes & $1.07(0.32-3.56)$ & 0.912 & $2.09(0.93-4.69)$ & 0.076 \\
\hline \multirow[t]{2}{*}{ Lymphovascular invasion } & No & Ref. & & Ref. & \\
\hline & Yes & $1.95(0.53-7.21)$ & 0.319 & $2.05(0.82-5.15)$ & 0.125 \\
\hline \multirow[t]{2}{*}{ Perineural invasion } & No & Ref. & & Ref. & \\
\hline & Yes & $1.6(0.48-5.34)$ & 0.443 & $3.11(1.41-6.9)$ & 0.005 \\
\hline \multirow[t]{2}{*}{ Resection margin } & Free & Ref. & & Ref. & \\
\hline & Infiltrated & $0.73(0.16-3.38)$ & 0.688 & $1(0.4-2.51)$ & 0.9978 \\
\hline \multirow[t]{2}{*}{ Lymph node ratio } & $<0.14$ & Ref. & & Ref. & \\
\hline & $\geq 0.14$ & $1.96(0.63-6.06)$ & 0.243 & $2.76(1.24-6.15)$ & 0.013 \\
\hline \multirow[t]{2}{*}{ Adjuvant treatment } & No & Ref. & & Ref. & \\
\hline & Yes & $0.11(0.04-0.35)$ & $<0.001$ & $0.28(0.13-0.61)$ & 0.002 \\
\hline
\end{tabular}

CI: Confidence interval

showed a significant difference in survival outcome between low risk $(<0.06)$ versus intermediate and high risk $(\geq 0.17)$ LNR. This highlights the need for intensification of adjuvant treatment in the management of such group of patients.

While we found a significant effect of adjuvant treatment when compared to no treatment on survival, we did not compare between radiotherapy and chemoradiotherapy as we thought that this comparison needs to be addressed in a prospective study. A significant relation was reported between LNR and survival (OS and DFS) in univariate analysis for all patients, but not with OS in node-positive cases. On the other hand, the absolute number of positive LNs and $\mathrm{N}$ stage were significant in survival analysis of all patients as well as node-positive patients.

These prognostic factors were investigated by Roberts et al who compared the number of positive LNs to the AJCC N staging and LNR in HNSCC patients using the surveillance, epidemiology, and end results (SEER) database ${ }^{26}$. They concluded that positive LNs number has a superior prognostic value in comparison to the AJCC N staging and LNR, and they recommended further modification of the staging system based on the number of positive LNs. In the aforementioned study, patients with 1 positive node had a lower risk versus higher risk patients with $>5$ positive LNs who had a worse survival ${ }^{26}$. In our study, the absolute number of positive LNs had an independent significant association with OS and DFS.

Two systemic reviews discussed the optimal cutoff value of LNR and LN yield without clear results. However, higher ratio was associated with worse prognosis regardless of the LNR cutoff value used ${ }^{27,28}$. In contrast, the study of Ebrahimi et al that was conducted on 201 patients with oral SCC found that LNR is useful in stratifying patients with $\mathrm{pN} 1$ into high and low risk to select adjuvant treatment. However, in pN2 cases, conventional $\mathrm{N}$ staging that reflects the size and laterality of involved nodes that were not considered in LNR, had a better predictor value of survival outcome. Moreover, it is difficult to accurately estimate the total number of involved nodes and nodal yield in the condition of multiple matted LNs which may negatively influence the accuracy of LNR ${ }^{29}$.

It is worth mentioning that it is challenging to setup optimal standards for the assessment of LN involvement and to select the best cutoff value of LNR, taking into consideration the variation in neck dissection types and 
the site affected by the disease. This is further complicated by its dependence on the quality of surgery and pathological examination and the absence of categorization of micrometastasis $<2 \mathrm{~mm}^{15,29}$. All these issues make LNR consideration, as a single value, in the decision of adjuvant treatment and prognosis a matter of debate. Further results from prospective studies or large databases of HNSCC patients are essential to set the potential significance of LNR as an independent prognostic factor in that cancer. The proper categorization and the selection of universal classification of LNR or LN grouping according to the tumor site and type of neck dissection, in association with other prognostic factors, are mandatory for the proper selection of patients who are candidates for adjuvant treatment.

The important limitations of our study are: the single center retrospective design, small number of patients, variation of types of neck dissection, multiple tumor sites and inadequate $\mathrm{LN}$ dissection in $35 \%$ of patients.

\section{Conclusion}

Lymph node ratio is an important prognostic factor for survival and disease failure in HNSCC. The absolute number of positive LNs has a valuable significant effect besides the TNM staging. Further prospective studies are mandatory to accurately validate the prognostic utility of LN status and to determine a universal cutoff value for the LNR. This may be needed for each specific disease site and type of neck dissection.

\section{FUNDING}

The authors did not receive funding for this study.

\section{CONFLICT OF INTEREST}

The authors have no conflict of interest to declare.

\section{REFERENCES}

1. Cooper JS, Zhang Q, Pajak TF, et al. Long-term follow-up of the RTOG 9501/intergroup phase III trial: postoperative concurrent radiation therapy and chemotherapy in high-risk squamous cell carcinoma of the head and neck. Int J Radiat Oncol Biol Phys. 2012; 84(5): 1198-1205.

2. Chen CC, Lin JC, Chen KW. Lymph node ratio as a prognostic factor in head and neck cancer patients. Radiat Oncol. 2015; 10: 181.

3. Greene F L, Trotti III A, Fritz AG, Compton CC, et al. AJCC Cancer Staging Handbook-7th ed., 2010. American Joint Committee on Cancer, Chicago, IL, USA 2009.

4. Amin M, Edge S, Greene F, et al. Eds. AJCC Cancer Staging Manual. $8^{\text {th }}$ ed. New York, NY: Springer, 2017.

5. Lydiatt WM, Patel SG, O'Sullivan B, et al. Head and neck cancers-major changes in the American Joint Committee on Cancer eighth edition cancer staging manual. CA Cancer J Clin. 2017; 67(2): 122-137.

6. Urban D, Gluck I, Pfeffer MR, Symon Z, Lawrence YR. Lymph node ratio predicts the benefit of post-operative radiotherapy in oral cavity cancer. Radiother Oncol. 2013; 106(1): 74-79.

7. Reinisch S, Kruse A, Bredell M, Lübbers HT, Gander T, Lanzer M. Is lymph-node ratio a superior predictor than lymph node status for recurrence-free and overall survival in patients with head and neck squamous cell carcinoma? Ann Surg Oncol. 2014; 21(6): 1912-1918.

8. Kassouf W, Agarwal PK, Herr HW, et al. Lymph node density is superior to TNM nodal status in predicting disease-specific survival after radical cystectomy for bladder cancer: analysis of pooled data from MDACC and MSKCC. J Clin Oncol. 2008; 26(1): 121-126.

9. Ooki A, Yamashita K, Kikuchi S, et al. Clinical significance of total gastrectomy for proximal gastric cancer. Anticancer Res. 2008; 28(5B): 2875-2883.

10. Vaccaro CA, Im V, Rossi GL, et al. Lymph node ratio as prognosis factor for colon cancer treated by colorectal surgeons. Dis Colon Rectum. 2009; 52(7): 1244-1250.

11. Woodward WA, Vinh-Hung V, Ueno NT, et al. Prognostic value of nodal ratios in node-positive breast cancer. J Clin Oncol. 2006; 24(18): 2910-2916.

12. Fleming ND, Frumovitz M, Schmeler KM, et al. Significance of lymph node ratio in defining risk category in node-positive early stage cervical cancer. Gynecol Oncol. 2015; 136(1): 48-53.

13. Sayed SI, Sharma S, Rane P, et al. Can metastatic lymph node ratio (LNR) predict survival in oral cavity cancer patients? J surg oncol. 2013; 108(4): 256-263.

14. Hua YH, Hu QY, Piao YF, Tang Q, Fu ZF. Effect of number and ratio of positive lymph nodes in hypopharyngeal cancer. Head Neck. 2015; 37(1): 111-116.

15. Hosni A, McMullen C, Huang SH, et al. Lymph node ratio relationship to regional failure and distant metastases in oral cavity cancer. Radiother Oncol. 2017; 124(2): 225-231.

16. Marres CC, de Ridder M, Hegger I, et al. The influence of nodal yield in neck dissections on lymph node ratio in head and neck cancer. Oral Oncol. 2014; 50(1): 59-64.

17. Ebrahimi A, Zhang WJ, Gao K, Clark JR. Nodal yield and survival in oral squamous cancer: defining the standard of care. Cancer. 2011; 117(13): 2917-2925.

18. Divi V, Chen MM, Nussenbaum B, et al. Lymph node count from neck dissection predicts mortality in head and neck cancer. J Clin Oncol. 2016; 34(32): 3892-3897.

19. Feng $\mathrm{Z}, \mathrm{Xu} \mathrm{QS}$, Wang $\mathrm{C}$, et al. Lymph node ratio is associated with adverse clinicopathological features and is a crucial nodal parameter for oral and oropharyngeal cancer. Sci Rep. 2017; 7(1): 6708.

20. Bhattacharyya $\mathrm{N}$. The effects of more conservative neck dissections and radiotherapy on nodal yields from the neck. Arch Otolaryngol Head Neck Surg. 1998; 124(4): 412-416.

21. Gil Z, Carlson DL, Boyle JO, et al. Lymph node density is a significant predictor of outcome in patients with oral cancer. Cancer. 2009; 115(24): 5700-5710.

22. Talmi YP, Takes RP, Alon EE, et al. Prognostic value of lymph node ratio in head and neck squamous cell carcinoma. Head Neck. 2018; 40(5): 1082-1090.

23. Jacobi C, Rauch J, Hagemann J, Lautz T, Reiter M, Baumeister P. Prognostic value of the lymph node ratio in oropharyngeal carcinoma stratified for HPV-status. Eur Arch Otorhinolaryngol. 2018; 275(2): 515-524.

24. Samani RE, Shirkhoda M, Hadji M, Beheshtifard F. The prognostic value of lymph node ratio in survival of headand-neck squamous cell carcinoma. J Res Med Sci. 2018; 23: 35 .

25. Yong-Hong HQ, Yong-Feng P, Qiu Tang ZF. Effect of number and ratio of positive lymph nodes in hypopharyngeal cancer. Head Neck. 2015; 37(1): 111-116.

26. Roberts TJ, Colevas AD, Hara W, Holsinger FC, OakleyGirvan I, Divi V. Number of positive nodes is superior to the lymph node ratio and American Joint Committee on Cancer $\mathrm{N}$ staging for the prognosis of surgically treated head and neck squamous cell carcinomas. Cancer. 2016; 122(9): $1388-1397$. 
27. Iocca O, Farcomeni A, De Virgilio A, et al. Prognostic significance of lymph node yield and lymph node ratio in patients affected by squamous cell carcinoma of the oral cavity and oropharynx: study protocol for a prospective, multicenter, observational study. Contemp Clin Trials Commun. 2019; 14: 100324.
28. Huang TH, Li KY, Choi WS. Lymph node ratio as prognostic variable in oral squamous cell carcinomas: systematic review and meta-analysis. Oral Oncol. 2019; 89: 133-143.

29. Ebrahimi A, Clark JR, Zhang WJ, et al. Lymph node ratio as an independent prognostic factor in oral squamous cell carcinoma. Head Neck. 2011; 33(9): 1245-1251. 